\title{
Requirements Prioritization Using Risk Assessment for Analyzing Requirements
}

\author{
Ow Li Lee, Massila Kamalrudin, Safiah Sidek
}

\begin{abstract}
Requirements elicited from requirements elicitation session with stakeholders are usually comes in bulk and it is impossible to execute them simultaneously. In addition, the requirements elicited are unfiltered and usually low quality including ambiguous, incomplete and unclear. The low quality of requirements are then refined in the next activity which is requirements analysis in requirements engineering. This paper aims to integrate requirements prioritization techniques focused on the factor of risk in requirements analysis since the early stage of requirements engineering. It is seems to have a little evidence on that requirements prioritization focus on the factor of risk in requirements based on our conducted literature review. This paper begins with elaboration on requirements prioritization, further to the aspects of requirements prioritization, criteria for best suited technique, a literature review on requirements prioritization techniques. We then proposed a framework for requirements analysis with the integration of requirements prioritization. A case study is elaborated for a better vision on the process of the proposed approach. Finally, this study is believed to produce a better quality of requirements from the requirements analysis process.
\end{abstract}

Index Terms: Requirements Analysis, Requirements Engineering, Requirements Prioritization, Risk Assessment.

\section{INTRODUCTION}

A large number of requirements need to be implemented simultaneously when they are elicited from the stakeholders. In this case, the most significant requirements elicited need to be prioritized so that they are met by the earliest release in software development. However, requirements prioritization is one of the most significant activities in requirements analysis whereby a large number of requirements needs to be prioritized in accordance to the limited resources in terms of time, budget and etc. . Requirements prioritization also aids in the implementation of a software system via preferential requirements of stakeholders. Various stakeholders are encouraged to participate in the system development for requirements prioritization in order to have the requirements to be executed in the right way according to their level of importance. On the other hand, it is impossible to execute a large set of requirements elicited from the stakeholders simultaneously, if the requirements are not prioritized. Requirements prioritization process is important to ensure the execution of requirements based on priority basis within the provision of limited resources. Software products developed based on the prioritized requirements can be expected to have a lower chance of being rejected. However, it is found that

Revised Version Manuscript Received on September, 2018.

Ow Li Lee, Universiti Teknikal Malaysia Melaka, Malaysia.

Massila Kamalrudin, Institut Pengurusan Teknologi \& Keusahawanan, Universiti Teknikal Malaysia Melaka, Malaysia.

Safiah Sidek, Institut Pengurusan Teknologi \& Keusahawanan, Universiti Teknikal Malaysia Melaka, Malaysia most of the companies do not have ideas on how to effectively assign priorities on the requirements. This paper is organized into seven sections. The first section elaborates the introduction and the second section defines requirements prioritization. The third section of our paper describes the aspects to be prioritized in requirements prioritization and followed by the criteria for a best suited technique in the next section. In addition, we also include the current requirements prioritization techniques for comparison in section 5 on our paper. We then proposed a framework for requirements prioritization in Section 6 provided with a case study in Section 7. We conclude our study in the last section, section 8 conclusion, in this paper.

\section{REQUIREMENTS PRIORITIZATION}

Firesmith explains that requirements prioritization as a process that provides perfect order for requirements implementation based on the requirements importance . In another word, Hudaib et al. define requirements prioritization as the ordering or schedule for executing requirements based on their priority or importance with respect to stakeholders' viewpoint . In a simpler explanation, requirements prioritization can be defined as the activity during which the most important requirements for the system should be identified . Based on our understanding, requirements prioritization is important to help the stakeholders to uncover to most important requirements and select the final candidate requirements within resource constraints. In addition, requirements prioritization also helps to discover requirements defects for example incorrect requirements, ambiguous requirements and etc. as the stakeholders need to communicate for requirements analysis and discussion.

According to Karlsson et al. , there are three general stages in requirements prioritization session:

\section{The preparation stage}

In this stage, a person structures the requirements in accordance to the principle of prioritizing techniques that possible to be adopted. In addition, a team and the leader are selected. The team leader needs to supply the requirements prioritization session with all the substantial information.

\section{The execution stage}

In the execution stage, the evaluation criteria must be agreed upon by the team before proceeding to the execution of requirements prioritization. The decision maker prioritizes the requirements by using the information supplied in the previous preparation stage. 


\section{The presentation stage}

The results gained from the execution stage are presented to those involved stakeholders.

\section{ASPECTS OF REQUIREMENTS PRIORITIZATION}

Requirements can be prioritized by taking a few different aspects into account. The aspect mentioned refers to a property or attribute of a certain project and its requirements that are being considered in requirements prioritizing. There are six common aspects found in prioritizing requirements, including the importance of requirements, penalty, cost, time, risk and volatility . It is easy to prioritize requirements solely based on one of the aspects mentioned above. For example, requirements prioritized based on the level of importance will be affected when it involves with other aspects such as cost. Customers are most likely change their mind on the requirements prioritization or the identification of high priority of requirements may need to be re-considered as less important if they are very expensive to carry out. Hence, it is important to not only consider the importance of requirements in prioritizing requirement, but also other aspects. We will elaborate on each of the aspects mentioned above for requirements prioritization consideration.

\section{Importance}

In prioritizing requirements based on their importance level, the stakeholders choose to implement the requirements based on their level of importance. The most important requirements will be implemented and the least important requirements will be implemented after.

\section{Penalty}

Penalty refers to the money that needs to be paid if the requirements are not fulfilled. Penalty is also one of the rather important aspects to be considered as some requirements may have low values but high penalty if failing to implement.

\section{Cost}

Cost is referred to the money spend on implementing the requirements or cost is usually expressed in terms of staff hours (effort) since the main cost in developing a software is much related to the number of hours spent.

\section{Time}

As we mentioned above, cost in developing software is usually related to number of staff hours.

\section{Risk}

It is not possible to deny that every project carries its own risk in developing. Every project carries a certain amount of risks. The impact of the risk must be considered carefully when determining the level of the risk. Risk management can be adopted in identifying the level of the risk in planning requirements into projects. There are a few risks including performance risk, process risk, schedule risk and others risk. Risk can be prioritized in terms of which requirement has the highest risk, moderate and lowest risk.

\section{Volatility}

Volatility of requirements are considered as part of risk factor and often handled as risk aspect. Minority of stakeholders think that volatility should be considered and analyzed separately in requirements prioritization process. Volatility of the requirements affects the stability and planning of a project and presumably increases the cost since changes made during project development increase the cost of the project. In addition, the cost of the project might be increase as the developers need to select an architecture suited to change of the aspect of volatility is known to be an issue .

\section{Other Aspects}

Based on our conducted literature regarding the aspects to be considered for requirements prioritization, the above listed aspects are the most important aspects but it is by no means exhaustive. For example, some company would like to consider the aspects of competence from the rivalry. Hence, the requirements will be interpreted differently for their level of importance.

\section{Combining Different Aspects}

In some of the work found in our literature, there are techniques combining at least two aspects mentioned above to prioritize requirements. For example, Karlsson and Ryan introduced a cost-value approach prioritizing cost and value (importance) to implement the requirements. In the same context, the planning game prioritizes importance, effort (cost) and risks using similar approach . In fact, there are many alternatives and aspects to be considered in prioritizing requirements. It is very much depend on the specific project, environment and situation of the company, goal and objectives of the project and etc.

There are works found and elaborated in Section 4.0 below for the current techniques to prioritize requirements adopting different types of aspects respectively. In our work, we would like to focus the aspect of risk in requirements prioritization. The aspect of risk is rather an important aspect as the risk originated from requirements are usually difficult to implement, combined with a lack of an efficient negotiation, incorrect budget or schedule, from unsuitable analysis of requirements and from poor quality design. The risk in requirements phase is usually intrinsic risk, which refers to the risk that can be managed in the project once they have been identified. In addition, requirements have the pervasive effect to affect the rest of the activities in project development if the requirements process is risky . Hence, we would like to focus on the risk factor for requirements prioritization, in requirements analysis activity in order to mitigate the risk since the early stage for a better quality of requirements. The risk in requirements is expected to be identified and resolved during requirements prioritization. The higher risk of requirements is required to be handled and implemented than those requirements marked with lower risk. We believe that the defects of requirements are minimized and a better quality of requirements via risk management in the early stage of requirements analysis activity through requirements prioritization. 


\section{CRITERIA FOR BEST SUITED TECHNIQUE}

There are studies on the topic of general requirements prioritization techniques and a comparison is made between the prioritization techniques with general factors concerned by the decision makers. Based on the result of the study conducted by Hudaib et. al and, a list of suggested factors to be specified as the best suited technique are:

1. Ease of use: Ease of use means how easy of the approach to be used in requirements prioritization. A value from the range of 1 to 8 indicates the degree of ease of use of a specified requirements prioritization technique. 1 refers to the high degree of ease while 8 refers to the low degree of ease.

2. The speed of showing results: The speed of showing results in another word is the complexity of the specific requirements prioritization technique. Its given value is from 1 to 8 and the smallest number gets the result in the fastest way and vice versa. Time is always a crucial factor in industry which makes the time consumption to generate the result a very important factor to judge a approach.

3. Size of requirement: In another word, the size of requirements also refers to the scalability. It indicates the size of the requirement set of the project and the given values are small, medium and large. Scalability is one of the most commonly discussed problems in several studies .

4. Accuracy: It refers to the degree of accuracy of the result. The values given are high accuracy, medium and less accuracy. It is important to consider the factor of accuracy as the incorrect results would imply wasted time.

5. Stakeholders' involvement: The participation of the stakeholders in requirements prioritization process is also considered as one of the factor. The given values are low, medium and high. The client are not aware of the cost and technical difficulties with the specific requirement and yet the requirement engineers do not know which requirements are the most important .

The five factors stated above are just a reference to build a requirements prioritization technique. There are others factors to be considered in building the ideal requirements prioritization technique based on different important level of the factors

\section{V.REQUIREMENTS PRIORITIZATION TECHNIQUES \& RESULTS}

There are a few requirements prioritization methods we found from literature study that we would like to include in this section. The simplest method for requirements prioritization technique found is Numerical Assignment Technique (NAT)and it has been mentioned by a larger number of studies. The requirements are classified into mandatory, desirable or inessential. In another words, the requirements also can be classified with a scale ranging from 1 to 5 whereby 1 is the least important and 5 is the most important. NAT is rather easy to implement for requirements prioritization but it does not support for scalability. It can only be used on a simple and unformal requirements prioritization. NAT also does not provide a significant value for requirements prioritization indication.

The Analytic Hierarchy Process (AHP) adopts pair wise comparison matrix in order to compute the relative value and

cost of respective requirements in respect to one another. AHP requirements prioritization method is considered as one of the more accurate method compared to other requirements prioritization methods as it includes a process to test the consistency of pair wise decisions. However, AHP does not support scalability as the number of pair wise comparison increases exponentially with the number of requirements.

MoScoW is another type of numerical assignment technique for requirements prioritization . In MoScoW, there are four priority groups which include MUST have, SHOULD have, COULD have and WONT have. Each requirements is placed in of the groups based on their priority.

Another simple and straightforward method is known as Cumulative Voting (CV) or 100 Point Method or Hundred Dollar Method. CV is a voting system whereby the stakeholders are required to vote in favor of the most important issues. The vote assigned to the issue represents the stakeholder's relative preference and hence requirements prioritization. This method is considered too simple for a real requirement to be prioritized in software project.

Beck introduced Planning Game with aim to aid stakeholders prioritize user stories in extreme programming. Basically, the requirements will be divided or sorted into 3 piles. The end result of the sorting will be a sorted list of requirements on ordinal scale. Planning game is relatively simple method for requirements prioritization, but it does not support for higher level goal setting and negotiation. In addition, planning game does not scale well for requirements management in large and complex system.

One of the prioritization techniques, also claimed as the best method, Value Oriented Prioritization (VOP) adopts a framework that provides a foundation for requirements prioritization and making decision regarding requirements. The framework adopted identifies business's core values and the relative relationships among those core values. VOP accesses and then prioritizes requirements via the framework. VOP provides visibility for all the stakeholders in making decision, emphasizes the core business value by eliminating lengthy discussion and arguments between individual requirements.

Binary Search Tree assists stakeholders to compare the relative value of individual requirements. This method is presented by Karlsson J., Wohlin C. and Regnell B. . It allows a relatively large set of requirements to be prioritized compared to other requirements prioritization techniques. The less important requirements will be inserted to the left and the more important requirements to the right. A prioritized list of requirements will be generated via depth-first traversal of a completed tree. Binary Search Tree is simple in implementation and support relatively large set of requirements for prioritization but it only provides a simple ranking for requirements without assigning any priority values. 
Researchers Duan et. al proposed a semi-automated technique to generate a list of prioritized requirements from a large set of requirements. The proposed approach is named as Pirogov. Pirogov borrowed the concept of triage from medical field to apply in requirements prioritization which referring to the practice of quickly and systematically classify victims from a disaster into groups for treatments. On the other hand, Pirogov adopts clustering technique to place requirements into multiple orthogonal categories that capture the diverse and complex. Pirogov is found to be more effective applied to the project with large number of unstructured requirements. Requirements of project that are carefully managed and elicited within a framework are not likely to benefit from Pirogov.

We have summarized all the techniques included in our literature study in the comparison Table 1 below.

\begin{tabular}{|c|c|c|}
\hline Techniques & Advantages & Disadvantages \\
\hline $\begin{array}{l}\text { 1. Numerical Assignment } \\
\text { Technique (NAT) }\end{array}$ & $\begin{array}{l}\text { - Easy for implementation } \\
\text { - High stakeholders' } \\
\text { participation }\end{array}$ & $\begin{array}{l}\text { - Low scalability } \\
\text { - Less accuracy }\end{array}$ \\
\hline $\begin{array}{l}\text { 2. Analytic Hierarchy } \\
\text { Process (AHP) }\end{array}$ & $\begin{array}{l}\text { - Suitable method for small } \\
\text { size requirements }\end{array}$ & $\begin{array}{l}\text { - Low scalability } \\
\text { - Time consuming } \\
\text { - Low stakeholders. } \\
\text { participation }\end{array}$ \\
\hline 3. MoScoW & $\begin{array}{l}\text { - Easiest method } \\
\text { - High stakeholders. } \\
\text { participation }\end{array}$ & $\begin{array}{l}\text { - Achieving group } \\
\text { consensus on definitions } \\
\text { and criteria can be } \\
\text { challenging } \\
\text { - Low scalability }\end{array}$ \\
\hline 4. Cumulative Voting (CV) & $\begin{array}{l}\text { - High accuracy } \\
\text { - High stakeholders' } \\
\text { participation }\end{array}$ & $\begin{array}{l}\text { - Does not cater for real } \\
\text { implementation } \\
\text { - Low scalability }\end{array}$ \\
\hline 5. Planning Game & - Simple & $\begin{array}{l}\text { - Does not support for } \\
\text { higher level goal setting } \\
\text { and negotiation } \\
\text { - Low scalability }\end{array}$ \\
\hline $\begin{array}{l}\text { 6. Value Oriented } \\
\text { Prioritization (VOP) }\end{array}$ & - Provides visibility & \\
\hline 7. Binary Search Tree & $\begin{array}{ll}\text { - } & \text { Simple } \\
\text { - } & \text { Reliable results } \\
\text { - } & \text { Support relatively large } \\
& \text { set of requirements }\end{array}$ & $\begin{array}{l}\text { - Only provides a simple } \\
\text { ranking for requirements }\end{array}$ \\
\hline 8. Pirogov & $\begin{array}{l}\text { - Effective for only } \\
\text { unstructured requirements }\end{array}$ & $\begin{array}{l}\text { - Does not cater for } \\
\text { common requirements }\end{array}$ \\
\hline
\end{tabular}

Table 1: Advantages and disadvantages for each requirements prioritization technique

Based on the analysis of the literature conducted on the topic of requirements prioritization, we found that the techniques or tools mentioned above generally work well on a small scale of requirements by using manual approach. It requires a lot of human effort in order to perform requirements prioritization and it always time consuming for requirements prioritization process.

\section{COMPARISON ANALYSIS OF THE TECHNIQUES}

There are a few authors select existing requirements prioritization techniques and compare the differences between the selected techniques in order to report on the best suited technique for requirements prioritization.

A decades ago, Karlsson J., Wohlin C. and Regnell B. conducted an evaluation of six different methods for prioritizing software requirements. All of the six methods are then categorized according to a number of criteria from a user's perspectives and AHP method is found to be the most promising method despite of its low scalability issue. However, the results yield from the evaluation in this study does not necessary reflect the current challenges faced in requirements prioritization process since it was conducted a decade ago.

Authors Khari and Kumar took a closer look at the six prioritization techniques including Analytic Hierarchy Process (AHP), Value Oriented Prioritization (VOP), Cumulative Voting (VP), Numerical Assignment Technique (NAT), Binary Search Tree (BST) and Planning Game (PG). They put all of the six selected techniques into controlled experiment with aim to understand the differences regarding ease of use, total time taken, scalability, accuracy and total number of comparison required to make decision for requirements prioritization. The five criteria mentioned will indicate the most suitable requirements prioritization technique. Based on their comparison, Value Oriented Prioritization (VOP) technique yields accurate result, high scalability and requires the least amount of time to make decision. Nevertheless, the evaluation of six requirements prioritization techniques is carries out independently from a real software project and it only involves a very small sample .Authors Achimugu et al. performed a deeper investigation on the existing requirements prioritization techniques and discovered that there are a lot of existing techniques suffered 
from a number of limitations. Even though there are more techniques are reported in their study, most of the techniques found are not reported in real settings yet.

Khan J. A. et al. examind eight requirements prioritization methods, with the aim to find the best technique, analytic network process (ANP), Analytical Hierarchy Process (AHP), Spanning Tree Matrix, Bubble Sort, Binary Search Tree and Priority Groups. The eight requirements prioritization methods are critically reviewed and they claimed that AHP technique to be the most reliable and promising technique for requirements prioritization. They are also aware of the low scalability for AHP technique when the requirements become larger.

The latest study found was conducted by Hudaib A. et al. on the eight popular techniques used to prioritize requirements. Their comparison study was conducted based on three criteria. The first criterion is based on questions related to ease of use, scalability, consistency, accuracy and the speed for each of the method compared. The second criterion included for their comparison refers to the participation of the stakeholders while the third criterion is number of requirements for requirements prioritization. A literature study on the eight requirements prioritization techniques was described and evaluation was conducted. They concluded that binary search tree as the best suited technique for requirements prioritization based on the model calculation included in their study.

As a result of our study, there seems to be a little evidence regarding which approaches for requirements prioritization preferred over the others . In addition, we also observed that there has been little progress on the theoretical or practical on the mechanism for requirements prioritization up to date .

\section{PROPOSED FRAMEWORK FOR REQUIREMENTS PRIORITIZATION}

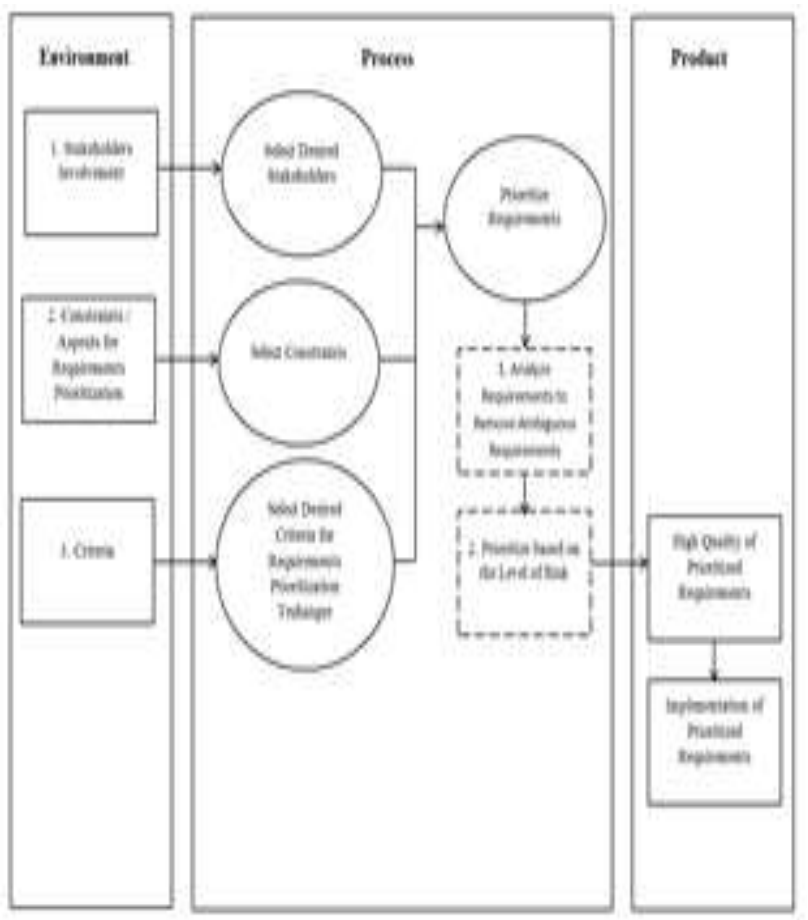

Figure 1: The conceptual Framework of Our Proposed Requirements Prioritization
Our proposed framework aims for an effective requirements prioritization process that is expected to produce a higher quality of requirements for implementation. We refer to the context variable in the study of for requirements prioritization in constructing our proposed framework. Our framework consists of three stages including environment, process and product. Stakeholder involvement, constraints / aspects for requirements prioritization and lastly criteria as below:

\section{Environment}

- Stakeholders involvement

A pool of available stakeholders will be shortlisted to be involved.

- Constraints / Aspects for requirements prioritization

There are constraints for requirements prioritization stated in 2.0 above.

- Criteria

There are five criteria suggested by for requirements prioritization stated in 3.0 above.

\section{Process}

- Select desired stakeholders

Desired stakeholders are decided in this stage for requirements prioritization process.

- Select Constraints

In our work, we focus on the constraints of risk. The requirements are prioritized based on the level of risk. Requirements labelled with higher risk will be implemented first than those requirements labelled with lower risk.

- Select desired criteria for requirements prioritization technique

Our proposed framework has a balanced focus on five of the factors for a best suited requirements prioritization technique.

- Prioritize requirements

When the desired stakeholders are selected, constraints are defined, criteria for requirements prioritization techniques are focused, requirements prioritization process is started. The requirements are analyzed in order to remove the ambiguous requirements. The requirements are further with prioritization based on risk labelled on each of them.

\section{Product}

- High quality of prioritized requirements

Requirements are analyzed and prioritized based on risk factor.

- Implementation of prioritized requirements

The prioritized requirements are ready to be implemented.

We also illustrate the conceptual framework of our proposed requirements prioritization in the next section with a case study for better understanding.

\section{CASE STUDY}

There are three stages in our proposed approach as shown above. The proposed approach begin with the first stage which refers to the environment. In the environment, requirements engineers select the desired or suitable

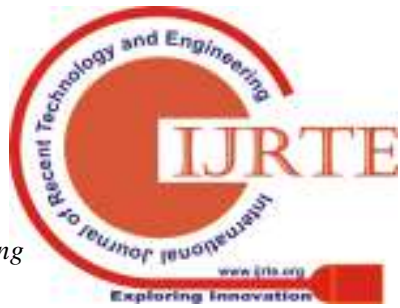


candidates among the stakeholders to be involved in the process of requirements analysis. In our proposed approach, we focus on the aspect of risk for requirements prioritization in the process of requirements analysis out of all the aspects mentioned in section 3.0. In addition, we have elaborated a list of criteria, in the previous section 4.0 to be followed in order to develop a better approach for requirements prioritization technique. Our proposed approach is tailored based on the criteria stated to produce a better quality of requirements.

The second stage of our proposed approach is the process of requirements analysis which is the core of the approach. The proposed approach checks and analyzes the requirements elicited from requirements elicitation for removing ambiguous requirements. Requirements engineers discuss and decide which requirements to be removed and which requirements to be proceeded. The analyzed requirements hence undergo the process of requirements prioritization. The requirements are labelled with the level of risk by the requirements engineers and stakeholders involved. The requirements are prioritized based on the level of the risk labelled.

The last stage of the proposed approach refers to the product of the process of requirements analysis. A high quality of the prioritized requirements is produced for the implementation of requirements by the requirements engineers. The process of requirements analysis thru risk assessment is completed.

\section{CONCLUSION}

Our paper discussed requirements prioritization in general, the aspects to be taken into account for prioritization and the criteria for best suited requirements prioritization technique. In addition, we also investigated the current techniques for requirements prioritization. However, we found that the techniques or tools mentioned above generally work well on a small scale of requirements using manual approach. It requires a lot of human effort in order to perform requirements prioritization and it always involves human errors during the process. We proposed a framework for requirements analysis integrating risk assessment. This approach is believed that it could help to produce a better quality of requirements.

\section{ACKNOWLEDGMENT}

We would like to thank UTeM Zamalah and UTeM PJP grant: PJP/2018/S01638 for funding this research.

\section{REFERENCES}

1. H. Amjad, M. Raja, Q. Mais Haj, and A. Abdulla, "Requirements Prioritization Techniques Comparison,' no. January, 2018.

2. D. Firesmith, "Prioritizing Requirements," vol. 3, no. 8, pp. 35-47, 2004.

3. P. Achimugu, A. Selamat, R. Ibrahim, and M. N. R. Mahrin, "A systematic literature review of software requirements prioritization research," Inf. Softw. Technol., vol. 56, no. 6, pp. 568-585, 2014.

4. M. Khari and N. Kumar, "Comparison of Six Prioritization Techniques for Software Requirements," J. Glob. Res. Comput. Sci., vol. 4, no. 1, pp. 38-43, 2013.

5. P. Berander, K. A. Khan, and L. Lehtola, "Towards a
Research Framework on Requirements Prioritization,"pp. 39-48, 2006.

6. J. Karlsson, C. Wohlin, and B. Regnell, "An evaluation of methods for prioritizing software requirements," vol. 39, pp. 939-947, 1998.

7. P. Berander and A. Andrews, "Requirements Prioritization," Springer, pp. 69-94, 2005.

8. J. Karlsson and K. Ryan, "A Cost-Value Approach for Prioritizing Requirements," 1997.

9. K. Beck and M. Fowler, Planning Extreme Programming Kent Beck. 2000.

10. K. Beck, "Change with Extreme Programming," no. c, pp. 70-77, 1999

11. I. M. Del Aguila and J. Del Sagrado, "Requirement Risk Level Forecast Using Bayesian Networks Classifiers," Int J. Softw. Eng. Knowl. Eng., pp. 1-24, 2010.

12. S. Amber, N. Shawoo, and S. Begum, "Determination of Risk During Requirement Engineering Process," J. Emerg. Trends Comput. Inf. Sci., vol. 3, no. March, pp. 358-364, 2012.

13. O. Li Lee, M. Kamaruldin, and S. Sidek, "The State of the Art of Emotion in Requirements Engineering," Int. Symp. Res. Innov. Sustain., 2018.

14. H. Sadia, M. R. Beg, and M. Faisal, "Requirement Risk Identification: A Practitioner 's Approach," Int. J. Comput. Appl., vol. 102, no. 15, pp. 13-15, 2014.

15. A. Shah and M. Bilal, "Systematic Literature Review on Risk Management in Security Engineering," no. September, 2018

16. K. Appukkutty, H. H. Ammar, and K. G. Popstajanova "Software Requirement Risk Assessment Using UML." 2005.

17. K. E. Wiegers, "First Things First: Prioritizing Requirements," no. September, pp. 1-6, 1999.

18. J. A. Khan, I. U. Rehman, Y. H. Khan, I. J. Khan, and S. Rashid, "Comparison of Requirement Prioritization Techniques to Find Best Prioritization Technique," Mod Educ. Comput. Sci., vol. 11, no. November, pp. 53-59, 2015.

19. P. Laurent, J. Cleland-huang, and C. Duan, "Towards Automated Requirements Triage," no. December 2015, 2007.

20. C. Duan, P. Laurent, and J. Cleland-Huang, "Towards automated requirements prioritization and triage," pp. $73-$ 89, 2009.

\section{AUTHORS PROFILE}

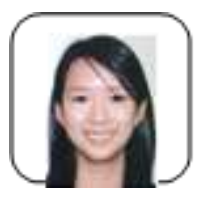

Li Lee Ow is currently a PhD candidate working under the supervision of Dr Massila Kamalrudin and Dr Safiah Sidek at the University of Technical Malaysia Melaka. She received her Bachelor in Computer Science in Software Development and Master of Science in Information and Communication Technology from University of Technical Malaysia Melaka. Her research interest lies in the field of software requirement, especially multi-lingual requirements, requirements prioritization and requirement analysis. She can be contacted at lilyow@hotmail.com

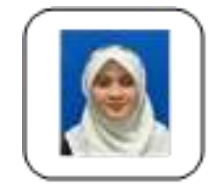

Massila Kamalrudin is born in Melaka, Malaysia. She is a Senior Lecturer of Software Engineering department and a research group leader of Innovative Software system \& Services group of UTeM. Her first Degree was Computer Science majoring in Software Engineering from Universiti Putra Malaysia in 2003, 
then completed her MSc in Computing and Software Technology in 2006 from University of Wales, Swansea. In 2011 she gained her PhD from University of Auckland, New Zealand in the area of Requirements Engineering within 3 years and did a post-doctorate study at Swinburne University of Technology, Melbourne Australia. She publishes in numbers of ISI/Scopus journals, IEEE/ACM conference proceedings and book chapters especially in the area of automated software engineering and requirements engineering. Her main interests of research are requirements engineering, security requirements, global software development and software tool and methodology. Dr Kamalrudin is also a member of IEEE and Malaysia Software Engineering Group (MYSEIG).

Safiah Sidek is a senior lecturer at the Centre for Languages and Human Development, Universiti Teknikal Malaysia Melaka. She currently holds the position of Deputy Dean of Academic at the center. She has a degree in Business Economics from Brock University, Canada and Masters in Science (TESL) from Universiti Putra Malaysia (UPM). She completed her PhD at Deakin University, Australia focusing on the use of online technology and changes in academics' identities. Her research interests include issues in globalisation, innovation and change, the use of online technology and research products commercialisation. She has been actively involved in research related to the use of technology. Besides being a research member for several research projects, she has led several research projects at the university level as well as the national level. At present, she is an active and key member of a research group, named Innovative Software System and Services (IS3). Her significant contribution in this research group is drawn from her expertise in the social aspect of the use of technology. She has been actively involved in several ICT product innovations by investigating users' acceptance and user's behaviour on the newly developed technology, particularly related to the Internet of Things. Among the research projects that she is currently involved are the investigation of a sustainable usage of health information systems in Malaysian hospitals and the investigation of users' behaviour on the use of new application in smart phones. Safiah is also a prolific writer and has written and co-authored several articles in journals indexed ISI/Scopus and proceedings as well as book chapters. 